\title{
The Practice Session Teaching Should Be Strengthen in the Course of Mechanical Design
}

\author{
Dong-wei WANG \\ Xiamen University Tan Kah Kee College, Zhangzhou, China
}

Keywords: Mechanical design, Practical link, Curriculum design, Teaching reform

\begin{abstract}
Mechanical design is a basic professional course of mechanical design for manufacturing and automation specialty. It is also a required course. Mechanical design plays a very important role in mechanical engineering technicians and mechanical industry. Therefore, it is of far-reaching significance to do a good job in the teaching of mechanical design course. This paper mainly describes the role of practice in the teaching of mechanical design, and puts forward the point of view of strengthening practice and improving teaching quality, which has certain guiding significance for the teaching reform of mechanical design course.
\end{abstract}

\section{机械设计课程应加强实践环节教学}

\author{
王东为 \\ 厦门大学嘉庚学院, 漳州, 中国
}

关键词: 机械设计; 实践环节; 课程设计; 教学改革

摘要: 机械设计是机械设计、制造及其自动化专业的专业基础课, 也是必修课。它对于机械 工程类技术工作者和机械工业有非常重要的作用。因此, 搞好机械设计课程的教学意义深远。 本文主要讲述了实践环节在机械设计教学中的作用, 提出了加强实践环节, 提高教学质量的 观点, 对于机械设计课程的教学改革有一定指导意义。

\section{1. 引言}

机械设计是机械设计、制造及其自动化专业的专业基础课，也是必修课。在机械设计课 程中有许多通用零部件, 这些零部件在各种机器设备中广泛使用, 但学生对机械零件由于缺 乏认识, 学习起来难度较大。虽然在机械类专业的教学体系中, 在机械设计课程之前的教学 已经进行了一些有关的专业基础课学习, 但由于机械设计课程内容比较多、教学课时有限, 学生对零、部件的感性认识不够, 教学相对较难。如果没有认真准备, 对相关机械零部件参 观学习, 也就不能较好地理解掌握机械设计的内容。对于某些特殊零部件的学习也是如此。 比如, 对轴类零件的结构设计, 要合理安排轴上零件的定位方式, 紧固方法, 使得轴上零件 的安装和拆卸要相对容易, 便于装配和维修保养。这些都要求与实践紧密结合。由于机械设 计课程的实践性较强, 所以加强与实践性教学环节, 理论结合实际, 对机械设计课程的教学 很有帮助 ${ }^{[1]}$ 。机械设计课程的教学, 应从加强实践性教学环节教学入手, 理论实践并重, 从 而提高机械设计课程的教学质量。

\section{2. 先修课程开设}

《机械设计》课程的讲解需要综合运用《高等数学》、《工程制图》、《工程材料》、 《互换性与测量技术》、《理论力学》、《材料力学》等基本知识, 这类先修课程的知识作 
为《机械设计》课程的基础, 非常重要。学习, 是一个循序渐进的过程。基础打不牢, 房子 盖歪了, 就会倒塌; 揠苗助长, 适得其反。在教学计划中, 必须将上述先修课程安排在《机 械设计》课程之前开设, 为学习《机械设计》课程作好充分的知识储备。先修课程开设不足, 学时不够, 给机械设计课程的讲解、学习带来困难, 对一些概念的认识学生感到茫然不知所 措。比如, 压缩力学教学内容, 学生对受力图、内力图、强度理论弄不明白, 在轴类零件的 结构和强度设计中, 就会茫然出错。

\section{3. 实践环节的教学}

根据机械类专业的教学计划, 机械设计课程之前安排参观学习和金工实习。实习中学生 看到各种机械加工设备, 通过对机械设备的操作使用, 产生感性认识。各类设备都是由许多 通用和一些专用零、部件组成的, 通过对机械设备的拆解、维修, 使得学生比较形象和直观 地了解各种通用件、专用件的具体应用场合和优缺点, 见多识广, 积少成多, 对于机械设计 的教学很有帮助。在设备维护保养中, 动员学生积极参与设备的日常维护保养, 在使用前后 进行维护。设备应定期进行二级保养, 三个月或半年一次。在学生参与设备维修保养的时候, 对各种零部件有了充分的认识, 再学习理论知识就容易理解和掌握。另一方面, 通过学生参 与设备的维护修理, 可以保护设备的正常工作, 减少故障, 提高设备的利用率和使用寿命。

\section{1 参观学习}

由于大多数学生上大学之前没有去过机械厂, 许多机械设备和零、部件没有见过, 对一 些机械设备的工作情况和零、部件的作用也不清楚。在学习了机械制图和大学物理等课程后, 对标准零、部件的结构和画法有了初步认识。在这个时候, 可以安排学生到机械工厂参观学 习。在参观学习过程中, 可以接触到许多机械设备, 了解到现在机械企业的发展状况, 对以 后的学习和找工作都有帮助。参观前首先进行安全教育和动员, 让学员遵守工厂安全制度和 规程, 避免危险发生。参观学习期间, 指导老师或企业技术人员可作一些讲解, 使学生对重 点设备和通用零部件有所了解。对一些能够看到的传动机构, 可以简要介绍他们的名称、分 类、工作原理和使用场合等, 使学生对各类机械传动产生兴趣, 对以后学习起到促进作用。

\section{2 金工实习}

金工实习是非常重要的教学实践环节。在金工实习中, 学生要学习几种类型的机械加工 设备的操作和维护保养方法。在具体的操作使用中, 与各种传动机构和通用的零部件亲密接 触, 眼到手到, 对他们的名称、类型和应用, 有了初步感受。这种体会, 对以后的教学环节 非常必要。金属切削机床是一种高精密的复杂设备, 是一切设备的母机。要学会正确使用和 维护保养, 按照操作规程正确使用设备, 养成良好的操作习惯, 避免事故发生。

厦门大学嘉庚学院有价值五千万的各类机加设备, 其中包括先进的数控加工机床, 可供 全校学生进行金工实习, 对于提高学生的操作动手能力和感性认知, 了解各类机械零件的加 工工艺过程, 很有帮助。学生们可以在金工实习过程中, 加工减速器轴, 齿轮等零件, 对于 后续机械设计的教学很有裨益。

厦门大学嘉庚学院机电工程系的学生, 在实习的过程中, 加工了许多减速器的零件。将 这些零件用非金属材料制作, 然后装配起来, 可以组装多台减速器, 作为教学模型供教学使 用。同学们在制作、拆装的过程中, 对基本的机械零件有了更加深入的认识, 对于减速器的 设计理解得更为清楚。

\section{3 实验教学}

机械设计课程设计环节之前有机械制图大作业、机械原理课程设计，与机械设计课程的 内容密切相关。机械制图大作业是从制图的角度画出机械装置的装配图, 机械装置中包含有 许多机械零、部件, 最基本的还是通用零、部件。机械原理课程设计主要是进行机械系统方 
案设计和机械运动、动力分析, 在进行机械系统方案设计时将涉及到机械传动方面的知识。 在这两个设计的基础上, 再进行机械设计课程设计, 前面的知识显得尤其重要。因此, 要求 学生能够按国家有关标准和机械行业标准, 绘制出正确的工程图。特别是手工制图, 要能够 一笔一笔画出来, 如手工绣花, 练好真功夫。CAD锦上添花, 能够熟练应用。机构原理要正 确理解掌握, 在设计中才能避免错误。

嘉庚学院机电工程系的学生在各级CAD大赛中取得了令人瞩目的成绩。CAD协会有专门 的设计室, 经常组织各类绘图软件的学习交流活动, 提高了同学们的设计能力。

嘉庚学院实验中心还有两台FDM快速成型机, 供教学使用。学生设计的各类零件都可以 加工出模型, 以检验设计是否存在问题。

在机械设计实验教学中, 重点把握各个实验项目的教学环节, 明确实验的目的、任务、 方法步骤, 以及具体的注意事项等。通过分组, 每组安排不同的时间, 有专门的实验教师讲 解、答疑, 指导同学按要求完成各项试验。

在机械设计课程的实验教学环节, 可以安排一下实验：螺栓连接与链、带传动实验、齿 轮传动实验、减速箱装拆及结构分析实验、机构模型及装备的参观、设计及编程、万向节传 动实验、螺旋弹簧特性分析实验等。

通过实验教学，使学生初步掌握常用传动机构的结构分析及设计方法，掌握一些通用零、 部件工作原理、特性、选型及计算方法; 培养学生能运用所学基础知识, 解决工程实际问题 的能力; 培养学生具有设计机械传动结构的能力及对某些典型零、部件进行分析, 并提出改 进措施。从而使学生了解常用机构和零、部件的实验过程; 初步掌握某些零、部件的性能测 试和结构分析方法, 加深对所学理论知识的理解。

厦门大学嘉庚学院机制专业的学生, 机械设计课程安排 4 个实验: 螺栓连接与带传动实验、 链与万向节传动实验、减速箱装拆及结构分析实验、螺旋弹簧特性分析实验。近机类的学生 安排 4 个实验: 传动实验、齿轮实验、机构模型参观及设计、参观加工设备及CAM编程。实 验教学对于理论教学很有帮助, 两者相辅相成。例如通过观察分析, 初步估计、测量齿轮的 模数大小, 对于齿轮零件可有更好的理解掌握。

\section{4 机械设计课程设计}

机械设计课程设计安排在机械设计课程理论学习后专门的教学实践周进行, 它是机械设 计课程的最后一个重要教学环节, 也是对学生较全面设计能力进行训练。机械设计课程设计 目的是: 通过课程设计, 巩固、加深和扩展有关机械设计方面的基础知识; 培养实际零部件 的设计技能; 训练综合运用理论，分析和解决各种问题的能力 ${ }^{[3]}$ 。

在机械设计课程设计过程中, 每个学生都应该明确设计任务和要求, 并拟定设计计划和 设计进度。设计过程中要独立思考、深入钻研, 主动地、创造性地进行设计, 反对照抄照搬、 敷衍塞责, 容忍错误存在或依赖教师。要求设计态度严肃认真, 有错必改。只有这样才能达 到教学基本要求, 在设计思想、设计方法和设计技能等方面得到良好的训练。

通过制定设计方案, 合理选择传动机构和零部件类型, 正确计算零件工作能力、确定尺 寸和选择材料, 以及较全面的考虑制造工艺、使用和维护等要求, 进行结构设计, 完成设计 任务。

编写设计说明书应包括: 确定传动装置总体方案, 选定电动机, 传动装置运动学、动力 学计算, 传动零件的设计计算, 轴、轴承、键联接的校核计算, 联轴器选择等内容。厦门大 学嘉庚学院机电系机械设计课程设计要求按规定格式编写设计说明书; 绘制装配图1张, 零件 工作图2张, 通常为轴、齿轮或箱体零件工作图。装配图用 1 号图纸, 一般要求用手工绘制。 零件图用 3 号图纸, 要求用 $\mathrm{CAD}$ 绘制。每个教师安排代一个小组做课程设计。教秘将课程班分 为若干个小组, 安排不同的教师指导。一般情况下, 每个小组不多于 15 名学生。

作为指导教师, 为了使学生能顺利地完成所布置的任务, 在设计过程中要加以指导。在 此之前应安排一次减速器装拆实验和观摩模型实物展览室, 增强学生的感性认识; 其他时间 
采取集体辅导与个别指导相结合的指导方式。要求每位学生在课程设计过程中, 充分发挥自 己的独立工作能力及创造能力, 对每个问题都应进行分析、比较, 并提出自己的见解和设计 方案。在课程设计过程中必须做到: (1)学会查阅和使用机械工程设计手册, 严格按照国家标 准设计、制图。(2)零件的选用或设计, 按照可靠性的要求, 确保使用安全。(3)按照零件的设 计步骤, 认真计算分析, 保证计算正确。(4)按预定计划完成课程设计。

在课程设计完成后指导教师要组织评审答辩, 根据学生编写的说明书、零件图、装配图、 答辩情况给成绩, 以检查和督促同学们按质按量完成设计任务。

上述几个教学实践性环节中经常遇到大量的通用零部件, 通过对他们的学习认知, 加深 学生们对通用零、部件的感性认识, 为后续课程的学习打下一个良好的基础。总之我们应加 强实践环节教学, 提高学生的感性认识和学习兴趣, 从而使他们理解和掌握机械设计这门课 程。

\section{4. 修订教学计划及教学大纲}

在制订教学计划和教学大纲时, 由于受人才培养方案对总学分的限制和其他因素的制约, 对各门课程的教学学时合理安排, 有一定难度。因此, 在制定人才培养方案时需经过充分的 讨论, 听取多方的意见和建议, 要能保证《机械设计》先修课程的必要学时, 和本课程的必 要学时 [2]。压缩先修课程的学时, 必然给后续的学习带来困难。由于对总学分的限制无法保 证先修课程学时, 则需留有一定学时, 在机械设计教学中补上先修课程相关欠缺内容, 确保 机械设计教学过程的完整性和连续性。任课教师需认真分析教学要求, 取舍教学内容, 突出 教学重点, 因材施教, 对学生需分层次区别对待, 制定较为合理的教学大纲, 保证教学质量。

在制订教学计划时, 要特别注意实践环节的教学。既要保证实验课的教学时间、教学质 量，又要保证课程设计环节的时间和课程设计教学任务的完成。

对于实验课的安排, 至少保证 8 学时, 安排 4 个实验。由教秘将学生分成几个小组, 以提 高教学效果。每个学生都要保证做 4 个实验、 8 个学时。这样就加大了实验课教师的工作量。 经过实验课教师的努力, 对每个小组, 都要详细讲解每个实验的目的、要求、具体操作步骤 和注意事项等。对于机制专业的学生，安排 4 个实验; 而对于近机类的学生，根据专业不同， 可以安排不同的实验项目，以适应各专业的具体要求。

对于机械设计课程设计的教学, 也要制订教学计划和教学大纲, 保证教学课时和教学设 施、教学用具的供应。厦门大学嘉庚学院机电工程系对于机械设计课程设计的教学, 专门安 排在实践周完成。对机制专业要求设计二级减速器, 提前一月布置设计任务, 并在理论教学 完成, 考试结束后, 安排两周的时间完成课程设计的任务。对于近机类专业的学生, 要求设 计一级减速器, 安排在两个实践周完成。

\section{5. 结束语}

机械设计与工程实际紧密结合。在课堂理论教学中, 也要结合工程实例加以讲解。在教 学安排上, 加强各个实践环节的教学内容。通过实习、实验教学、课程设计等, 加强学生对 机械设计课程的理解。加强实践环节, 有利于提高教学质量, 对于机械设计课程的教学改革 有指导意义。

\section{References}

[1] Yang Baoxiang, Brief analysis on the course teaching reform of the fundamentals of mechanical design [J]. China science and education innovation guide, 2008(01).

[2] Li Jiangong, Du Minghua, The basic idea of "mechanical design" course teaching reform [J]. Journal of hebei institute of technology (social science edition), 2002(z1). 
[3] Zhang Ming, Ren Jijun, Li Xiuhong, Research on mechanical design teaching reform and cultivation of innovative talents $[\mathrm{J}]$. Journal of taiyuan university of technology (social science edition), 2006(04). 